\title{
Integration of Value Co-creation into the e-Learning Platform
}

\author{
Eliza Annis Thangaiah, Ruzzakiah Jenal, Jamaiah Yahaya \\ Faculty of Information Science and Technology \\ Universiti Kebangsaan Malaysia, Bangi, Selangor, Malaysia
}

\begin{abstract}
The e-learning platform is a technology used in most academic institutions. The e-learning platform provides services as an alternative to conventional methods. Previous studies have primarily focused on using and accepting e-learning among consumers and developing tangible attributes on the platform. Platform attributes should be available to engage with all users, leading to innovative ideas and improvement in the value offerings to users if well used. Therefore, this study explores the service science perspective in terms of co-creation for an e-learning platform. The concept of Service-Dominant Logic and value co-creation is adopted to explore and extract the elements and factors that are collectively applied to the model. The concepts illustrate how user value is co-created through the value propositions on the platform and value drivers for the users. The findings help identify the components for value proposition on the platform: enrichment, interaction, personalization, and environment. Meanwhile, the components of value drivers for actors are engagement, resources, experience, and goals. Then, the proposed components are used to develop an e-learning conceptual model. A service-driven model of elearning will be a significant input to develop an effective platform that provides co-creation opportunities to its users. Future research is to identify the critical features available on the e-learning platform from the users' view.
\end{abstract}

Keywords-e-Learning; co-creation; S-D Logic; value propositions; value drivers; actors

\section{INTRODUCTION}

Recently, e-learning technology has been in high demand since the Covid pandemic hit the world. It is widespread recognition that E-learning plays a decisive role in supporting and engaging teaching and learning among its users. Students and teachers initially perceived face-to-face learning as the ultimate way of teaching and learning, but they have to find alternatives since the restriction order is applied. The objective of e-learning systems is to improve the educational system, enhance students' and teachers' learning, boost the education system, and improve students' performance. Teachers and students, as primary users of the education system, need to adapt to survive in the ever-changing technology environment. They need to be agile to adjust, respond, and be resourceful in working together and find practical learning for the institutions. By collaborating to develop information, users promote to transform information into knowledge and eventually get values.

Since its introduction, e-learning has gone through various adaptation processes to strengthen the implementation process and technology evolving from time to time. Users can access learning materials, search for information, collaboration, and experience irrespective of physical location limitations to deliver knowledge. Besides, technology and computing help educators prepare students for 21st-century life lessons.

Most developers focus on tangible items to develop elearning platforms or websites, such as technology [1] and internationalization [2], while value to the user and institutions is less considered [3]. Although online platforms are vastly rising, yet insufficient active contributors and continuous input of material or information [4]. A different perspective of the elearning model from the value view can be considered so that e-learning feature development meets the implied value. It is reported that students stated e-learning did not have the desired features and was also harder to use compared to Facebook [5]. Thus, services are only valuable if used and not based on what is offered, and hence user involvement in system development may accomplish a successful system. The value of the system exists in the stakeholders' cognitive space. Values are unique among individuals but can influence the user's behaviour in using e-learning.

In Service-Dominant Logic (S-D Logic), creating value co-creation (VCC) together is key to generating value by integrating their value with others and developing a new one [6]. With VCC, all users are part of the creators of value when using the system. According to [7], the concept of value co-creation in academic virtual learning environments has been discussed less frequently. To convert the traditional teacher-student models, in which teachers determine the learning resources, they can participate in VCC's educational processes into a flexible structure and an active learning environment. Thus, to find the platform that caters based on user's active participation, value co-creation focusing on user value strategy is proposed. Positive values instilled in the user's mind will guide them towards a proper attitude. The elearning platform services need to be used to deliver value [8]. A service has to have value to fulfill the user's needs. Further, studies linking education by using the concept of S-D Logic are still poorly implemented [9].

This paper will describe the factors of VCC in value proposition on the platform and value drivers from the users in using e-learning, which would lead to creating values for themselves and would benefit the institutions eventually. As [10] pointed out, service providers do not just make value proposition but also involves the actors who are users or contributors to produce values for themselves. It is needed to get feedback from the user to make them feel close, and there is a need to use the services on the platform. 
This paper is structured as follows: Section 2, "Literature Review" outlines the topics on e-learning, service-dominant Logic, and value co-creation. Section 3, "Methodology" describes the methodology employed to develop the conceptual model. Next, Section 4, "Result and Discussion" draws the outcome and discussion about the e-learning conceptual model. Lastly, Section 5, "Conclusion" points toward the overall conclusion and following plot for the research.

\section{LITERATURE REVIEW}

\section{A. E-learning}

E-learning is a web-based technology and application to enable learning and teaching [11] delivered through technology such as the internet, intranets, audio, video and conferencing, virtual classrooms, and digital collaboration. Web-based or mobile-based learning has become common in education. It can take many platforms, from massive open online courses (MOOCs) to a virtual learning environment (VLE) and learning management system (LMS), and many others [12].

In learning, teachers determine the learning resources into a flexible structure and an active learning environment to participate in the educational processes in virtual academic learning environments [7]. Collaborative and virtual learning environments provide a dynamic platform of interaction and conversation for students and teachers. For a successful system, e-learning should provide a platform that enables qualitative two-way communication between students and teachers and amongst students themselves. Thus, teachers' perceptions as providers must change, allowing students to be active contributors and enabling collaboration to occur effortlessly.

\section{B. Service-Dominant Logic (S-D Logic)}

The traditional view in marketing was Goods-dominant Logic; consumers are provided with their value [10]. The latter S-D Logic claims that value is always co-created with the partnership with users. [13] added the value-in-use in Goods-dominant Logic lacks the firm-customer interactions. The customer must participate by utilizing a product or service in the value exchange process to create value.

Based on S-D Logic, the main component is 'the customer is always the co-creator of value, which means creating value is an interactional process requiring active participation of both the customer and the supplier. In this study, the researched relationship is between teacher and student, student and student, and teacher and teacher. They are the primary users of the e-learning platform and are called actors. Users are categorized as operant resources in S-D Logic, integrating skills and knowledge into the co-creation process into the elearning platform's activities. Teachers' roles are not as providers and directors of the whole process, but they also become participants. Students' and teachers' perceptions and involvement as value co-creators can be linked to some foundational premises (FP). It is considered service value cocreators in S-D Logic based on ten FPs [14]. For example, FP1 is "Service is the fundamental basis of exchange," is a relevant premise for e-learning because e-learning provides services to all matters involving skills and knowledge. Also, FP10: "value if always uniquely and phenomenologically determined by the beneficiary" shows each user of e-learning platform are different, and their respective experience will add value to the platform.

\section{Value co-creation (VCC)}

In the value construct, there is a relationship with the cocreation element. Co-creation is needed, as various platforms provide space for virtual communities, yet many still lack sufficient active contributors and a continuous supply of knowledge content. Based on the value concept in the new marketing logic, value is not created solely by the firm but built with the customers during their usage of products and interactions with different actors. The value is produced in the customer sphere during consumption in response to the service provider's proposition value. Therefore, these value attributes are directly related to customer feelings and attitudes developed towards the service offered. [15] mentions VCC and the tools facilitating VCC activities have increased interest from information systems (IS) scholars and business practitioners. Researchers have been studying co-creation in various studies of information technology, such as in elearning [16], [17], Internet of Things [18], information systems [15], and social media [19].

Showing co-created material is a real need with a real impact, so the student and teachers can see that working together is worthwhile. This active participation means incorporating engagement, experience, resources, and goals into the activities; they guide the co-creation process themselves and take more responsibility for the activities to be co-created with the other participants. Virtual communities' studies identify two co-creation behaviours: searching for information through the community and, secondly, by participating in the community by generating and sharing content with other members [8]. Thus, it is vital to identify the features that would enable users to use e-learning to have closeness and create a sensory and emotional connection while using e-learning. The firm can develop only a value proposition, but the user determines the value of the offering through its usage.

Users are more informed, connected, and empowered than before; due to Internet technologies, they have access to new tools that enable them to co-create with others. The level of user participation in co-creation varies depending on the user's experience, engagement, resources, and goals. Further, it will influence them whether to continue using the platform for good or not.

This study derived VCC for the e-learning platform from interaction, enrichment, environment, and personalization for its primary users: teachers and students. Every user is unique; they tend to have their minds and ideas, contributing to their desires, experience, and future expectations. When various users work together with their different backgrounds and create new knowledge, it would develop users' values. Students have individual opinions about learning; thus, they need a platform that enables them to share and contribute to education by participating, improving their learning, thinking skills, understanding concepts, and creating knowledge [7]. In 
detail, the researchers' model illustrates how user value is cocreated through the value propositions on the platform and value drivers for the users. Besides, a study by [20] identified the need for co-creation in the e-learning environment.

\section{METHODOLOGY}

The process of developing the conceptual model was organized into three phases: input, activity, and output, as in Table I. The flow of the model development is shown in Fig. 1.

TABLE I. Phases of DeVeloping a Conceptual Model

\begin{tabular}{|c|c|c|}
\hline Input & Activity & Output \\
\hline $\begin{array}{ll}\text { - } & \text { Selection of } \\
\text { primary } \\
\text { source studies } \\
\text { - } \\
\text { Identify } \\
\text { theory and } \\
\text { models }\end{array}$ & $\begin{array}{l}\text { - Inspect and identify } \\
\text { the relevant studies } \\
\text { and models based on } \\
\text { keywords. } \\
\text { - Identify suitable } \\
\text { constructs and } \\
\text { components }\end{array}$ & $\begin{array}{l}\text { - e-learning } \\
\text { conceptual model } \\
\text { based S-D Logic } \\
\text { and VCC }\end{array}$ \\
\hline
\end{tabular}

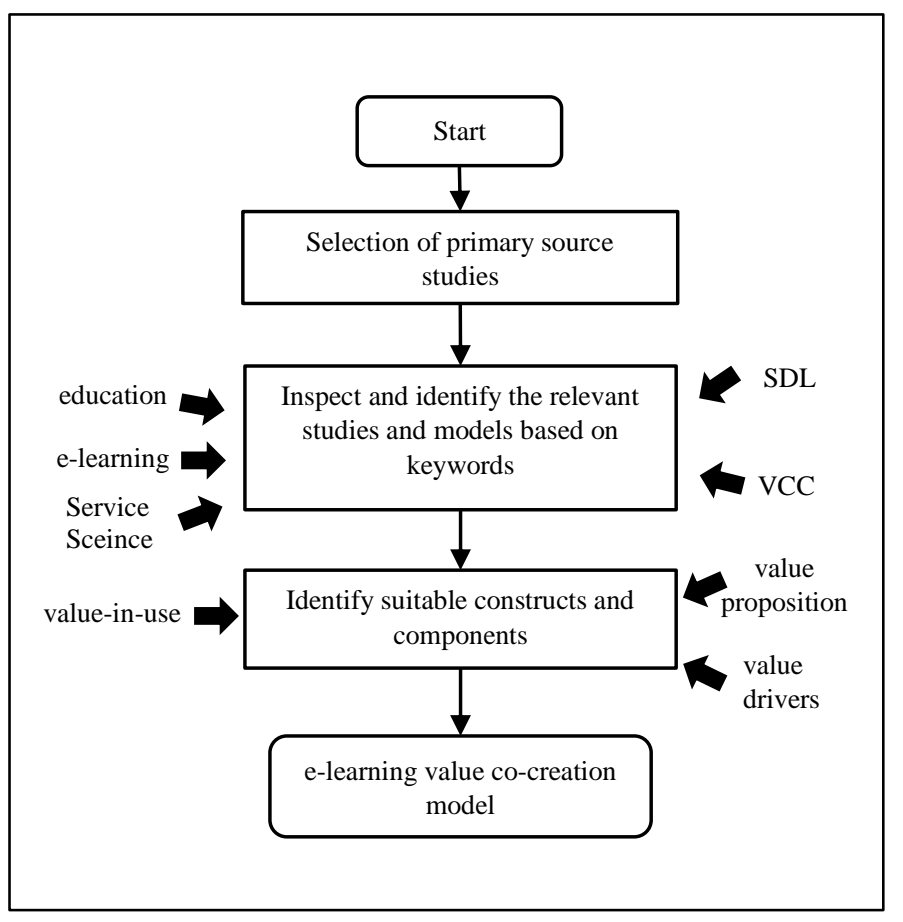

Fig. 1. The Flow of Model Development.

In selecting primary source studies, research databases, available search engines, and reliable websites were identified. This included the articles published by Sage Journals, Web of Science, Science Direct, Springer Link, Taylor and Francis, Emerald and Wiley. Next, academic papers, books, thesis, and related English and Malay language reports were selected. Keywords used were: service science, service-dominant Logic, e-learning, and education. All of the papers were available in electronic format, thus could be easily discovered using the keywords. Content analysis of all the items was handled to identify the elements and factors from the perspective of service science that could contribute to the value proposition on the e-learning platform and could lead value drivers to actors to contribute. Factors are examined in such can be used to develop the e-learning conceptual model embedding the concepts of service-dominant Logic and value co-creation.

\section{RESULT AND DisCUSSION}

S-D Logic and VCC have been proposed as the vital factor to develop a successful service or product. Since e-learning is a service platform, it may benefit from involving users' input in the development stage. Users need to play an important role and create value with others. Therefore, the views of students and educators as stakeholders are needed in building an elearning model. The joint contribution of ideas from students and instructors can build an e-learning model by determining users' values while using e-learning.

Therefore, a new approach needs to be considered in the elearning platform by studying the value element of co-creation through students' and instructors' value element approaches. The conceptual model's elaboration will be discussed in Subsection A. Value Proposition and B. Value Drivers.

\section{A. Value Proposition}

Platforms play a significant role in involving users, gathering them in the co-creation process, for sharing knowledge related to product or service usage. Platform with virtual environments for co-creation offers new opportunities by providing access to social media, i.e., content and interactions created via highly accessible web-based technologies. A platform can also create content that appeals to other users to use products or services while meaningfully enhancing the co-creation process. The technology on the platform must be taken advantage of to stimulate user's participation.

A value proposition is an opportunity for value-creating benefits delivered by an organization to its customers [21]. Value propositions facilitate the VCC process and do not have value by themselves. Once users accept a value proposition, they are an integrator of the value proposition (offered by the service provider) with their other resources to create value. In this study, four value propositions proposed are enrichment, interaction, personalization, and environment.

1) Enrichment: Enrichment on the e-learning platform refers to the information and features offered to generate knowledge to be more attractive, interactive, and suitable for learning. The content presentation provides easy management to users while using the e-learning platform. Information conveyed to users includes content management, how learning content is delivered, and enrichment of learning through more media towards users who aim to achieve goals [22]. Enrichment of information can shape individuals' development in conducting an independent collection of resources for current results and future planning [23]mastery of information relating to users and systems, thus publishing value elements. Good learning management can help stimulate information delivery and create learning materials involving all users [24]. Enrichment on the platform can be presented on updated content, user information, an organized file system, achievement space, notification space, 
reminders, and security. From the S-D Logic perspective, enrichment on the platform is a service offered involving skills and knowledge and enrichment of attributes/features, also known as operant resources. Information enrichment on platform can be represented through FP1 of S-D Logic, where the services offered on the platform involve skills and knowledge. As well as FP4, which states that operant resources are fundamental to the competitive advantage.

2) Interaction: Interaction through active user communication is a vital process of creating shared values, and the quality of interaction is fundamental to the creation of shared values of users. Online platforms such as e-learning enable interaction and collaboration between actors in cocreation [25]. From the point of view of S-D Logic, the users are co-creator of values and sources of integration, and they can share based on their level of experience, knowledge, and exposure [26]. Nowadays, students can access multiple resources to develop their understanding and further enhance sharing in the learning process [7]. Moreover, students are prone to search for information and no longer depend on just receiving end; they want their voices to be heard. In an elearning platform, interaction creates an interactive learning environment for developing material content or learning material based on tacit knowledge about the subject matter, allowing VCC communication between teachers and students. Meaningful interaction between teachers and students, students and students, and teachers and teachers significantly strengthens students' sense of membership and influence.

There are various opportunities for users to communicate with available technology, such as comment sections, notification, gaming, frequently asked questions, and others [27]. It could promote using the e-learning platform for a more extended period. Interactions between users in the community are essential for value creation; therefore, it is structured to find opportunities to co-create with users. [8] recommended having maximum interactivity so that users feel crucial, their response is taken into consideration, and they play an essential role within the community. From the S-D Logic perspective, FP6 states that the client is a co-creator of values and through this interaction, VCC can be achieved and supported. Meanwhile, FP9 says that everyone involved in the activity is a source of integration. FP11 states the value of co-creation is the result of coordination between actors and organizational creation.

3) Personalization: Personalization in web-based interactive environments has been considered a key element in enabling effective and efficient user engagement and applied to learning content, learning resources, and development activities [28]. Personalization is a process that allows users to access and store information based on various personal characteristics of the user and provide unique value and benefits to users based on needs and backgrounds. Personalization of e-learning will enable users to experience and, in turn, also contribute to the learning process. The merging of the personalization concept to e-learning technology empowers the learner to have a learning process that can be adapted to their needs [29]. The attribute that can be represented by personalization on platforms such as customize the interface, personalized recommendation, progress bar, online personalized feedback, and a sticky note, to name a few. Therefore, e-learning equipped with personalization must meet a wide range of individual needs and preferences to enable VCC.

From the S-D Logic perspective, service orientation through user personalization achieves its benefits by making the user's own choices. E-Learning allows selecting learning materials that meet their level of knowledge, interest, and what they need to know to perform more effectively in an activity. E-Learning is more focused on the learner, and it is more interesting for the learner because it is information that they want to learn. From the S-D Logic perspective, FP10 states that values are unique, and phenomena depend on the user's benefits, while FP8 states the service is customercentric. Its relationships and personalization enable users to achieve benefits by making their own choices.

4) Environment: A conducive e-learning platform environment is essential because it allows users to access information, resources, and services. From the S-D Logic point, an e-learning platform is a medium of service dissemination, and operant resource is the fundamental resource in inter-organizational and community. The environment on a quality e-learning platform plays a vital role in determining the use of e-learning [30]. The environment must give users a pleasant and acceptable environment to influence users regarding the platform's quality. The elearning platform's environment refers to the medium or system developed to enable user operant and operand resources involving operational features that can create the process of integrating resources independently through value creation. Thus, the environment should consist of service quality elements, information quality and system, and technology quality. Well-designed e-learning may provide an environment that supports users' motivations, such as attractiveness, so users can choose to develop VCC based on their experience, resources, engagement, and goals [8]. FP3 can be associated with the e-learning platform as a service dissemination mechanism from the S-D Logic perspective, and FP4 states that operant resources are vital for competitive advantage.

\section{B. Value Drivers}

Actors as users are the person who uses services or products and their role in contributing on e-learning platform by using the services provided. Besides, actors derive value from their use of products or services, and therefore value delivery still represents a value creation type. Service exchanges can involve the co-creation or the self-creation of value, depending on the level of contribution provided by each actor in the service exchange [31]. Value-in-use means that value for the user is created or appears during participation [32] which indicates that the user is involved in the value 
creation process [13]. Thus, as users use the platform, they together create co-creation value while benefiting through value-in-use. Actors have a role in contributing to the elearning platform through value factors such as involvement, resources (skills and knowledge), experience, and goals.

1) Engagement: Engagement involves a commitment of time, energy, and the ability to configure operand and operant resources and an essential co-creation element. Actors' engagement on platforms includes posting comments and reviews, giving a rating, watching videos, and attending online classes. When users get engaged, it builds and strengthens the relationship and influences user faithfulness, and is expected to impact users' intentions toward future co-creation in other ways. Subsequently, they may gain knowledge related to the cognitive benefits of information acquisition. Students' participation in their learning process has been recognized as enhancing the educational process's quality and results [33]. Co-creators engagement in co-creation activities depends largely on their expectations and perceived motivations [34].

Further, actors would be motivated by rewards such as gifts, points, or social benefits from the title, status, and social esteem they may receive. They may desire to enhance their sense of self-improvement and enjoyment. Co-creation between actors can increase actor's engagement with the platform and further engage them to use it longer. A positive attitude builds good encouragement towards the institution [35]. Student engagement is considered crucial in optimizing the student experience, enhancing learning, and linking with high-quality learning outcomes and shared value creation.

2) Experience: Experience can be defined as an essential element in creating shared values, and the basis for working together is consumers' experience when using the products or services provided [16]. There is no value created in S-D Logic until product/services are used; thus, the experience is essential for value determination. Further, value comes from the knowledge shared, and continuous usage builds a collection of experiences. With experience, prepare users mentally to learn and apply personal learning to successfully perform current jobs and tasks. The user experience is affected when the user has had a direct or indirect relationship with a product/service and relates new behaviours to past experiences [36]. According to [37], participation in an online platform such as brand communities includes posting reviews and comments, give a rating, sharing experience, and others. Researchers acknowledge that positive experiences may benefit the organization while using the platform and increase user co-creation experiences [15]. Besides, when users have experience with a service, they would likely seek other activities on their next visit and enhance usage [38].

3) Resources: An actor who uses anything to establish value creation is called a resource [10] and anything an actor can draw on for support [39]. Resources comprise tangible, natural, and static resources and intangible and dynamic human ingenuity and appraisal functions. There are two types of S-D Logic resources: operand and operant resources [40].
From an e-learning perspective, operand resources are the tangible items that actors use to utilize, such as devices, internet connection, facilities provided, and users. Meanwhile, operant resources are resources that actors use to produce mental or physical skills and knowledge in increasing organizational competitiveness. Shortly, the user uses any operant resources to act on operand resources to get values.

In S-D Logic, two FPs, which are FP4 and FP9, are linked to resources. FP4 states, "operand resources are the fundamental source of strategic benefit, and FP9 states, "all social and economic actors are resource integrators [41]." In elearning usage, users may invite other users to share their resources, cultivate resource sharing, and enable innovation to learn the material and extract value [42]. Tangible resources include lending equipment and intangible resources such as clicking like sharing, commenting, sharing ideas, and receiving opinions and statements. Shared learning material on the platform will allow users to retrieve and transfer material anytime and anywhere, enabling content to be more reusable and customizable.

The co-creation of the learning process and material can help produce improved material in line with other teachers' and students' actual requirements towards innovating the platform's services.

4) Goals: Goals refer to the desire to fulfil and motivate individuals to obtain knowledge. With a goal in mind, the user wants to learn and adapt to changes. [43] Studies indicate that students' achievement goals (performance or learning goals) are critical determinants of their attitude (e.g., satisfaction, perception, happiness), cognitive (e.g., critical thinking, information literacy), and affective goals (e.g., personal wellbeing, pleasure). When users' performance goals value highlighted and believed they had the high ability, they responded to overcoming the obstacles.

Interestingly, students' beliefs about their abilities, whether high or low, were irrelevant. Students sought to increase competence and opted for more challenging tasks to gain a learning goal's value. Motivation can influence learning, and the user tends to use products/services that they consider valuable. When users actively participate in learning activities, they prepare themselves for future academic pursuits and add exposure. Different users may have various underlying goals to use the VCC platform and engage in VCC [44]. Thus, the writer aims to find out the VCC in e-learning among vocational school teachers and students.

\section{The E-learning Conceptual Model}

Fig. 2 shows the e-learning conceptual model compromising the value proposition on the platform and value drivers for actors and their relationship. By adapting VCC as theoretical foundations, the model is divided into the value proposition and value drivers. The upper section shows the platform's value proposition elements, while the bottom section shows the value drivers for the platform's users. The model is developed to systematically illuminate how identified value drivers have the intention to use e-learning. The roles of users as main actors are to contribute to the e-learning 
platform through engagement, share resources, experience, and goals. The concept of VCC prioritizes the value created when users use the service. At the same time, providers can enhance value-in-use by providing value proposition in platform features and supporting users to contribute continuously. Indirectly, a learning cycle exists to the user while using e-learning, and correspondingly, they together create VCC while benefiting through value-in-use.

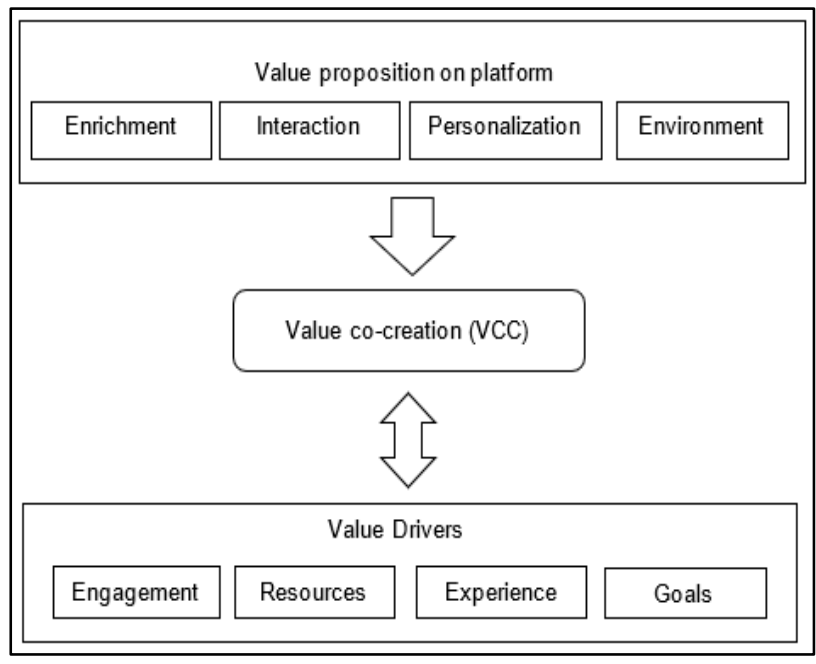

Fig. 2. E-learning Conceptual Model based on S-D Logic and VCC.

\section{CONCLUSION AND Future Plan}

The Covid-19 pandemic has changed the lifestyle of many, including in the education system. Moving into online learning took some time for everyone since everyone is forced to use it. Most of the method used to develop e-learning platforms was focused on tangible items on e-learning platforms while value to the user and institutions is less considered. As mentioned, the concept of S-D Logic is still poorly implemented, especially with education. Thus, as this paper explored e-learning a platform that offers services in education, it would provide a new perspective in S-D Logic and VCC. The emergence of the area of S-D Logic and value co-creation, has thrived in imploring the research community to handle research the concepts, theory and methodologies of co-creation. This motivation has led us to analyze the idea of user's value in using e-learning services and search for a suitable value proposition on platform and value drivers for and from users that contribute the essence of value. This paper aims to identify value propositions components on the platform and value drivers for and by actors. When designing an e-learning platform, gathering VCC must be beneficial to the user's potential of value. However, the e-learning conceptual model does not cover all the other users, such as developers or system admin, due to the need to know the platform's primary users' values, teachers and students. Both the actors could contribute as participants and providers to the platform by being engaged, sharing experience and resources, and fulfilling their goals. Therefore, a new approach needs to be considered in the e-learning platform by studying the value element of co-creation through students' and teachers' value element approaches.
The next step is to identify the attribute on the e-learning platform that is crucial that can be implemented on the platform as a value proposition and lead actors to value. Further, the attribute of e-learning is matched to the dimension of the value proposition factors. Considering this research outcome would guide the developers of the critical features of the e-learning platform. Future research is to identify the critical features available on the e-learning platform from the users' view by using the means-end chain theory and laddering technique. Identifying the attributes with users will further motivate users to anticipate it is worthwhile using the service. The findings can help system developers to build a platform for institutes to manage the learning platform and understand how to create values for users.

\section{ACKNOWLEDGMENT}

The author would like to give appreciation to the Center for Software Technology and Management (SOFTAM), Faculty of Information Science and Technology (FTSM), Universiti Kebangsaan Malaysia (UKM), who have funded this paper through grants research (GGP-2020-038).

\section{REFERENCE}

[1] P. C. Sun, K. C. Hsing, and F. Glenn, "Critical functionalities of a successful e-learning system - An analysis from instructors' cognitive structure toward system usage," Decis. Support Syst., vol. 48, no. 1, pp. 293-302, 2009.

[2] H. Nordin and D. Singh, "The Internationalization of E-Learning Websites: A Methodology," New Zeal. J. Comput. Interact. NZJCHI, vol. 1 , no. $12,2016$.

[3] S. Motamarri, "Consumer Co-creation of Value in mHealth (Mobile Health) Service," J. Creat. Value, vol. 3, no. 1, pp. 63-76, 2017.

[4] C. J. Chen and S. W. Hung, "To give or to receive? Factors influencing members' knowledge sharing and community promotion in professional virtual communities," Inf. Manag., vol. 47, no. 4, pp. 226-236, 2010.

[5] I. T. Awidi, M. Paynter, and T. Vujosevic, "Facebook group in the learning design of a higher education course: An analysis of factors influencing positive learning experience for students," Comput. Educ., vol. 129, pp. 106-121, 2019.

[6] Y. Zhang, M. Zhang, N. Luo, Y. Wang, and T. Niu, "Understanding the formation mechanism of high-quality knowledge in social question and answer communities: A knowledge co-creation perspective," Int. J. Inf. Manage., vol. 48, no. July 2018, pp. 72-84, 2019.

[7] M. Ranjbarfard and M. H. Sureshjani, "Offering a framework for value co-creation in virtual academic learning environments," Interact. Technol. Smart Educ., vol. 15, no. 1, pp. 2-27, 2018.

[8] N. Rubio, N. Villaseñor, and M. J. Yague, "Does Use of Different Platforms Influence the Relationship between Cocreation Value-in-Use and Participants' Cocreation Behaviors? An Application in Third-Party Managed Virtual Communities," Complexity, vol. 2019, pp. 1-15, 2019.

[9] T. Beckman and A. Khare, "A Service-Dominant Logic and Value Cocreation Approach for Online Business Education," in Springer International Publishing AG 2018, 2018, pp. 21-35.

[10] R. F. Lusch and S. Nambisan, "Service Innovation: A Service-Dominant Logic Perspective," MIS Q., vol. 39, no. 1, pp. 155-175, 2015.

[11] S. Ghavifekr, "Factors affecting use of e-learning platform (SPeCTRUM) among University students in Malaysia," Educ. Inf. Technol., vol. 22, no. 1, pp. 75-100, 2017.

[12] M. Hussain, W. Zhu, W. Zhang, and S. M. R. Abidi, "Student Engagement Predictions in an e-Learning System and Their Impact on Student Course Assessment Scores," Comput. Intell. Neurosci., vol. 2018, 2018.

[13] C. Grönroos, "Value co-creation in service logic: A critical analysis," Mark. Theory, vol. 11, no. 3, pp. 279-301, 2011. 
[14] S. L. Vargo and R. F. Lusch, "Why ‘service’?,” J. Acad. Mark. Sci., vol. 36, no. 1, pp. 25-38, 2008.

[15] D. Pacauskas, "The Role of ICT in the Value Co-Creation Process," Aalto University publication series, 2016.

[16] E. Y. Chou, C. Y. Lin, and H. C. Huang, "Fairness and devotion go far: Integrating online justice and value co-creation in virtual communities," Int. J. Inf. Manage., vol. 36, no. 1, pp. 60-72, 2016.

[17] Muriati Mukhtar, Mohamed Nazul Ismail, and Yazrina Yahya, "A hierarchical classification of co-creation models and techniques to aid in product or service design," Comput. Ind., vol. 63, no. 4, pp. 289-297, 2012.

[18] M. T. Delgado et al., "Value Co-Creation Mechanisms," IoT Eur. Platf. Initiat., p. 75, 2016.

[19] W. A. Z. W. Ahmad, M. Mukhta, and Y. Yahya, "Evaluating the applicability of a social content management framework: A case analysis," Int. J. Adv. Comput. Sci. Appl., vol. 9, no. 12, pp. 339-345, 2018.

[20] E. A. Thangaiah, R. Jenal, and J. Yahaya, "Penerokaan Penggunaan EPembelajaran dalam Kalangan Pelajar dan Pengajar TVET - Satu Kajian Awal (Investigating the E-Learning Usage Among TVET Students and Teachers - A Preliminary Study)," Akademika, vol. 90, no. 3, pp. 5-18, 2020.

[21] F. Buttle and M. Stan, Customer relationship management: concepts and technologies. Routledge, 2019.

[22] T. Tuunanen and H. Govindji, "Understanding flow experience from users requirements," Behav. Inf. Technol., vol. 35, no. 2, pp. 134-150, 2016.

[23] Mohamed Nazul Ismail, Yazrina Yahya, and Muriati Mukhtar, "Nilai cipta-sama sistem pengurusan pembelajaran," J. Teknol. (Sciences Eng., vol. 60, pp. 21-29, 2013.

[24] R. Mcdaniel, J. R. Fanfarelli, and R. Lindgren, "Creative Content Management: Importance, Novelty, and Affect as Design Heuristics for Learning Management Systems," IEEE Trans. Prof. Commun., vol. 60, no. 2, pp. 183-200, 2017.

[25] R. Bidar, A. Barros, and J. Watson, "Co-creation of services: an online network perspective," Internet Res., vol. ahead-of-p, no. ahead-of-print, 2021.

[26] Prahalad C.K. and V. Ramaswamy, "Co-creating unique value with customers," Strateg. Leadersh., vol. 32, no. 3, pp. 4-9, 2004.

[27] M. M. Daniels, E. Sarte, and J. Dela Cruz, "Students' perception on elearning: A basis for the development of e-learning framework in higher education institutions," IOP Conf. Ser. Mater. Sci. Eng., vol. 482, no. 1, 2019.

[28] H. M. Truong, "Integrating learning styles and adaptive e-learning system: Current developments, problems and opportunities," Comput. Human Behav., vol. 55, pp. 1185-1193, 2016.
[29] S. Ouf, M. Abd Ellatif, S. E. Salama, and Y. Helmy, "A proposed paradigm for smart learning environment based on semantic web," Comput. Human Behav., vol. 72, pp. 1-23, 2016.

[30] H. Ataburo, A. S. Muntaka, and E. K. Quansah, "Linkages among EService Quality, Satisfaction, and Usage of E-Services within Higher Educational Environments," Int. J. Bus. Soc. Res., vol. 7, no. 3, pp. 926, 2017.

[31] N. Zainuddin, L. Tam, and A. McCosker, "Serving yourself: value selfcreation in health care service," J. Serv. Mark., vol. 30, no. 6, pp. 586600, 2016.

[32] N. Bendapudi and R. P. Leone, "Psychological Implications of Customer Participation in Co-Production,” J. Mark., vol. 67, pp. 14-28, 2003.

[33] S. A. Taylor, G. L. Hunter, H. Melton, and S. A. Goodwin, "Student engagement and marketing classes," J. Mark. Educ., vol. 33, no. 1, pp. 73-92, 2011.

[34] R. Bidar, J. Watson, and A. Barros, "Classification of service cocreation systems: An integrative approach," Int. Conf. Adv. Commun. Technol. ICACT, pp. 333-340, 2017.

[35] S. L. Huang and C. T. Chen, "How consumers become loyal fans on Facebook," Comput. Human Behav., vol. 82, pp. 124-135, 2018.

[36] A. F. Payne, K. Storbacka, and P. Frow, "Managing the co-creation of value,” J. Acad. Mark. Sci., vol. 36, no. 1, pp. 83-96, 2008.

[37] S. Kamboj, B. Sarmah, S. Gupta, and Y. Dwivedi, "Examining branding co-creation in brand communities on social media: Applying the paradigm of Stimulus-Organism-Response," Int. J. Inf. Manage., vol. 39, no. October 2017, pp. 169-185, 2018.

[38] R. A. Rather, L. D. Hollebeek, and S. M. Rasoolimanesh, "First-Time versus Repeat Tourism Customer Engagement, Experience, and Value Cocreation: An Empirical Investigation," J. Travel Res., 2021.

[39] M. Blaschke, M. K. Haki, S. Aier, and R. Winter, "Value Co-creation Ontology — A Service-dominant Logic Perspective," Multikonferenz Wirtschaftsinformatik 2018, pp. 398-409, 2018.

[40] S. L. Vargo and R. F. Lusch, "Institutions and axioms: an extension and update of service-dominant logic," J. Acad. Mark. Sci., vol. 44, no. 1, pp. 5-23, 2015.

[41] S. L. Vargo and R. F. Lusch, "Service-dominant logic: continuing the evolution," J. Acad. Mark. Sci., vol. 36, no. 1, pp. 1-10, 2008.

[42] A. Sood, "Value As An Aid For Understanding Perceived Service Quality Of Digital Services: The Jyu Faculty Of Information Technology As A Case Study,” University Of Jyväskylä, 2019.

[43] K. M. Judson and S. A. Taylor, "Moving from Marketization to Marketing of Higher Education: The Co-Creation of Value in Higher Education," High. Educ. Stud., vol. 4, no. 1, pp. 51-67, 2014.

[44] M. Zhou, X. Cai, Q. Liu, and W. Fan, "Examining continuance use on social network and micro-blogging sites: Different roles of self-image and peer influence," Int. J. Inf. Manage., vol. 47, no. January, pp. 215232, 2019. 